Research Article

\title{
Determination of Antiradical Activity, Total Phenolic, and Total Flavonoid Contents of Extracts and Fractions of Langsat (Lansium domesticum Coor.) Seeds
}

Yamin*
Ruslin
Sabarudin
Nurramadhani A. Sida
Henny Kasmawati
La Ode Muhammad Diman
Department of Pharmacy, Universitas
Halu Oleo, Kendari, South East
Sulawesi, Indonesia
*email: yamin_taeri75@ymail.com
Keywords:
Antiradical
DPPH
Lansium domesticum
Total flavonoid content
Total phenolic content

\begin{abstract}
Lansium domesticum Coor. is a fruit species from the Meliaceae family, which is a tropical plant native to Southeast Asia. Local citizens call it langsat, longkong, or $d u k u$ and have used it as traditional medicine. The seeds of L. domesticum are used as a fever medicine, its bark is used to treat scorpion sting, and its leaves are used to repel mosquitoes. Because of its various uses, it is necessary to explore the antiradical potential of $L$. domesticum seeds. This study aims to determine the antiradical potential of $L$. domesticum seeds extract and fractions by using the 2,2-diphenyl-1-picrylhydrazyl (DPPH) method and to discover compounds that act as antiradical. Lansium domesticum seed powder was macerated with methanol, and then the extract was concentrated using a rotary evaporator and fractionated by $n$-hexane and ethyl acetate. The antiradical assay was conducted on extract and fractions by using DPPH radicals. Phenolic and flavonoid contents from extract and fractions were also tested. The ethyl acetate fraction obtained strong antiradical potential with an $\mathrm{IC}_{50}$ value of $8.938 \pm 0.031$ $\mu \mathrm{g} / \mathrm{mL}$. Total phenolic and flavonoid contents of ethyl acetate fraction were higher with values of $58.25 \pm 0.501 \mathrm{mgGAE} / \mathrm{g}$ sample and 75.123 $\pm 0.175 \mathrm{mgQE} / \mathrm{g}$ sample, respectively. Correlation of phenolic and flavonoid contents, which inhibited radicals had $R^{2}$ values of 0.9182 and 0.7658 . Ethyl acetate fraction of L. domesticum seeds had very strong antiradical activity. Further isolation is expected to be conducted to discover which compounds are the most responsible as antiradical.
\end{abstract}

Received: June 27th, 2020

Accepted: September $18^{\text {th }}, 2020$

Published: November 30th, 2020

(c) 2020 Yamin, Ruslin, Sabarudin, Nurramadhani A. Sida, Henny Kasmawati, La Ode Muhammad Diman. Published by Institute for Research and Community Services Universitas Muhammadiyah Palangkaraya. This is an Open Access article under the CC-BY-SA License (http://creativecommons.org/licenses/by-sa/4.0/). DOI: https:// doi.org/10.33084/bjop.v3i4.1500

\section{INTRODUCTION}

Lansium domesticum Coor. (synonym: L. parasiticum) is a fruit species from the Meliaceaefamily, which is a tropical plant native to Southeast Asia. Local citizens call it langsat, longkong, or $d u k u$ and have used it as traditional medicine (Manosroi et al., 2012; Tilaar et al., 2018). Oil from the peel of L. domesticum fruit is used to treat diarrhea, dysentery, and malaria (Khoo et al., 2016; Yapp \& Yap, 2003). The seeds are used as a fever remedy, the bark is used as medicine to treat scorpion sting (Tilaar et al., 2008), and the leaves are used to repel mosquitoes (Klungsupya et al., 2015). Besides that, some studies showed that $L$. domesticum has antimalarial (Saewan et al., 2006), antiproliferation (matrix metalloproteinase-2 inhibition on human oral epidermal carcinoma) (Manosroi et al., 2013), anti-oxidative, and analgesic activity (Apridamayanti et al., 2018).

In previous studies, it has been reported that the peel of L. domesticum contains several types of terpenoids (Klungsupya et al., 2015). Its seeds contain terpenoids and 
phenolic compounds such as flavonoids (Klungsupya et al., 2015; Nur et al., 2017), while its bark contains alkaloid metabolites, saponins, tannins, flavonoids, and triterpene (Apridamayanti et al., 2018). Secondary metabolic compounds of polyphenols derived, such as flavonoids, tannins, stilbene, coumarin, and lignin, are abundant in its leaves, stems, flowers, and fruit, having an essential role in counteracting free radicals (Pandeya et al., 2018). These polyphenols' antioxidant properties are due to the polyphenol compound's redox properties, which acts as a reducing agent by donating its hydrogen (Piluzza \& Bullitta, 2011).

The body needs antioxidants because they can delay substrate oxidation by inhibiting initiation and propagation (Pham-Huy et al., 2008; Widodo et al., 2020). Synthetic antioxidants, such as beta-hydroxy acid (BHA), tert-butyl hydroquinone (TBHQ), propyl gallate (PG), and butylated hydroxytoluene (BHT), have been used extensively in the world. However, these synthetic antioxidants have side effects, such as carcinogenic and cytotoxic effects on the heart and lungs (de Oliveira et al., 2010; Sulastri et al., 2018). Additionally, BHA and BHT also have low solubility and moderate antioxidant activity (Sannigrahi et al., 2010). Therefore, current research focused on discovering new antioxidant compounds from natural products that exhibit high activity and lower toxic effects than synthetic compounds (Rohman et al., 2010).

Natural products with antioxidant properties have been reported, such as L. domesticum fruit (Manosroi et al., 2012), Moringa oleifera extract (Fitriana et al., 2016), and peel of Nephelium lappaceum (Mistriyani et al., 2018). Ethyl acetate fraction and tetranortriterpenoid compounds isolated from the dichloromethane fraction of $L$. domesticum showed antimalarial activity against Plasmodium falciparum (Klungsupya et al., 2015; Saewan et al.,2006). Extracts and fractions from Persea americana peel have also shown antimalarial activity. This research aims to determine the potential of antiradical activity from extracts and fractions of $L$. domesticum seeds.

\section{MATERIALS AND METHODS}

\section{Extraction}

Lansium domesticum seeds were obtained from fruit traders in Fruit Market Wua-Wua, Kendari, Southeast Sulawesi, Indonesia. The seeds of L. domesticum are then crushed into a powder and dried. Furthermore, $L$. domesticum seed powder was macerated using methanol for $3 \times 24$ hours. Every 24 hours, the macerate was filtered, and the solvent was replaced. Then, the macerate was concentrated using a rotary evaporator at $40^{\circ} \mathrm{C}$ to obtain crude extract.

\section{Fractionation}

As much as $40 \mathrm{~g}$ of $L$. domesticum seed crude extract was partitioned using the gradient elution liquid-liquid fractionation method. First, the seed extract was partitioned using a separatory funnel with $n$-hexane, followed with ethyl acetate, and water fraction as the remaining fraction. Each fraction was evaporated with a rotary evaporator into crude fractions. The working method in a diagram is presented in Figure 1.

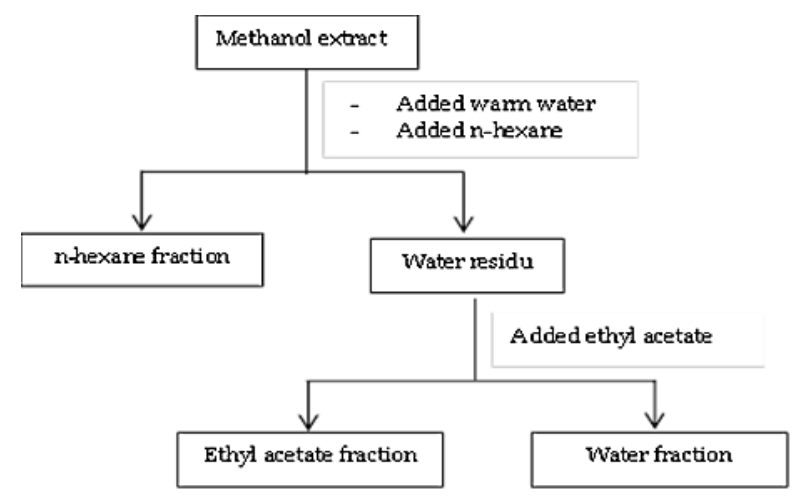

Figure 1. Fractionation scheme of L. domesticum seeds extracts and fractions

\section{Phytochemical screening}

Phytochemical screening was conducted to determine the profile of secondary metabolites in L. domesticum 
seeds extracts and fractions. Phytochemical screening methods were performed based on previous research by Yamin et al. (2020).

\section{Alkaloid test}

Lansium domesticum seeds' extract and fractions were inserted separately into $1 \mathrm{~mL}$ test tubes and added three drops of Dragendorff's reagent. The formation of brown precipitate indicated the presence of alkaloid.

\section{Flavonoid test}

The extract and fractions of $L$. domesticum seeds were inserted separately into test $1 \mathrm{~mL}$ tubes and added with $0.2 \mathrm{~g}$ of magnesium powder and $2 \mathrm{~mL}$ of concentrated $\mathrm{HCl}$. The formation of red, orange, and green solutions indicated the presence of flavonoid.

\section{Terpenoid test}

The extract and fractions of L. domesticum seeds were inserted separately into $1 \mathrm{~mL}$ test tubes and added with $0.5 \mathrm{~mL}$ of acetic acid anhydride and $2 \mathrm{~mL}$ of concentrated sulfuric acid. The formation of green, bluish, and brown solutions indicated the presence of terpenoid.

\section{Tannin test}

The extract and fractions of $L$. domesticum seeds were inserted separately into $1 \mathrm{~mL}$ test tubes and added with 1 $\mathrm{mL}$ of $1 \%$ ferric chloride solution. The formation of blue to black solution indicated the presence of tannin.

\section{Saponin test}

The extract and fractions of $L$. domesticum seeds were inserted separately into $1 \mathrm{~mL}$ test tubes and added with 2 $\mathrm{mL}$ of hot water, then cooled and shaken for ten seconds. It was declared positive for saponin if the fume generated stabilized in less than ten minutes.

\section{Determination of antioxidant activity with DPPH}

The antioxidant activity was method according by (Rohman et al., 2010) with modified. As much as $1 \mathrm{~mL}$ from each sample solution was briefly taken and added with $3 \mathrm{~mL}$ methanol p.a., then $1 \mathrm{~mL}$ of $0.6 \mathrm{mM} \mathrm{DPPH}$.
Then, the samples were shaken until homogeneous. After that, the samples were incubated for 30 minutes in a dark room at room temperature. The absorbance of each solution was measured at $515 \mathrm{~nm}$ wavelength. The following equation calculated the power of antioxidants:

$$
\% \text { Inhibition }=\frac{A b s_{\text {control }}-\boldsymbol{A b s _ { \text { sample } }}}{A \boldsymbol{b} \boldsymbol{s}_{\text {control }}} \times 100 \%
$$

Abscontrol is absorbance of control Abssample is absorbance of sample

Therefore, the percentage of inhibition was plotted with the concentration $(\mu \mathrm{g} / \mathrm{mL})$ to obtain the linear regression equation of $y=b x+a$. The $\mathrm{IC}_{50}$ value was obtained by replacing $y$ with 50 and calculated the $x$ value. The $\mathrm{IC}_{50}$ is defined as the concentration of the sample that is needed to inhibit $50 \%$ of DPPH radical.

\section{Determination of total flavonoid content}

Flavonoid contents in extract and fractions of $L$. domesticum seeds were determined using a colorimetric method according to Saeed et al. (2012) with modified. Briefly, $10 \mathrm{mg}$ extract and $10 \mathrm{mg}$ fractions were dissolved with $10 \mathrm{~mL}$ methanol p.a. Then, $1 \mathrm{~mL}$ from each sample was added with $3 \mathrm{~mL}$ of methanol p.a., $0.2 \mathrm{~mL}$ of $10 \%$ aluminum chloride, $0.2 \mathrm{~mL}$ of potassium acetate $1 \mathrm{M}$, and distilled water to sufficient volume to $10 \mathrm{~mL}$. The sample was allowed to stand for 30 minutes, then the absorbance of the sample was measured at $439 \mathrm{~nm}$ wavelength with three replications. The absorbance value was plotted in the linear regression equation of the standard calibration curve with quercetin as standard. Thus, flavonoid contents were expressed as $\mathrm{g}$ quercetin equivalent (QE)/100 g sample.

\section{Determination of total phenolic content}

Phenolic contents in extract and fractions of $L$. domesticum seeds were determined using a spectrophotometric method according to Parthasarathi \& Park (2015) with modified. Briefly, $1 \mathrm{~mL}$ from each sample concentration series was taken, then $0.4 \mathrm{~mL}$ of Folin-Ciocalteu reagent 
was added into the samples. The mixture was shaken and allowed to stand for eight minutes. As much as $4 \mathrm{~mL}$ of $7 \% \mathrm{Na}_{2} \mathrm{CO}_{3}$ solution was added and shaken until homogeneous. Then, water was added until the volume reached $10 \mathrm{~mL}$. Absorbance was measured using a UVVis spectrophotometer at $647 \mathrm{~nm}$ wavelength with three replications. Phenolic content was expressed as g gallic acid equivalent (GAE)/100 g sample.

\section{RESULTS AND DISCUSSION}

The phytochemical screening results of $L$. domesticum seeds showed that the methanol extract, $n$-hexane, ethyl acetate, and water fraction positively contained flavonoids, alkaloids, tannins, and terpenoids. Meanwhile, the results of the saponin test on the extract and fractions were negative. These results are consistent with those reported by Nur et al. (2017). The result of phytochemical screening is shown in Table I.

Table I. Phytochemical screening of L. domesticum extract and fractions

\begin{tabular}{lcccc}
\hline \multirow{2}{*}{ Testing } & \multicolumn{4}{c}{ Extract/fraction } \\
\cline { 2 - 5 } & Methanol & $\begin{array}{c}n \text { - } \\
\text { hexane }\end{array}$ & $\begin{array}{c}\text { Ethyl } \\
\text { acetate }\end{array}$ & Water \\
\hline Flavonoid & + & + & + & + \\
Alkaloid & + & + & + & + \\
Tannin & + & + & + & + \\
Terpenoid & + & + & + & + \\
Saponin & - & - & - & - \\
\hline
\end{tabular}

$(+)$ : presence; (-): absence of phytochemicals

Measurement of antioxidant activity using DPPH radicals in this study was carried out after 30 minutes of incubation. This treatment allows all species involved in the reaction of antioxidants with radicals to have reacted entirely. The parameter used to determine the antioxidant activity was $\mathrm{IC}_{50}$ from extract and fractions of L. domesticum seeds. The $\mathrm{IC}_{50}$ is defined as the concentration of antioxidants in inhibiting radicals by 50\% (Olugbami et al., 2014). The smaller $\mathrm{IC}_{50}$ value indicated the potent antioxidant in extract or fractions (Maisuthisakul et al., 2007). The standard antioxidant used in this study was vitamin C.
Table II showed the $\mathrm{IC}_{50}$ values of $L$. domesticum seed extract and fractions. The data in the table exhibited extract and fractions of L. domesticum seeds are classified in the category of very strong antioxidants, as stated by Molyneux (2004). According to the data of $\mathrm{IC}_{50}$ shown in Table II, ethyl acetate fraction made a very strong contribution as an antioxidant compared to the $n$-hexane fraction, water fraction, and methanol extract, whose values were $8.938 \pm 0.031 ; 8.938 \pm 0.031 ; 13.898 \pm 0.81$; and $14.624 \pm 0.456 \mu \mathrm{g} / \mathrm{mL}$, respectively. These were in line with research that stated that the ethyl acetate fraction had strong antioxidant power compared to other solvents' fractions. Several ethyl acetate fractions with such strong antioxidant activity have been reported on Enhydra fluctuans Lour (Sannigrahi et al., 2010), Pandanus conoideus Lam (Rohman et al., 2010), Oroxylum indicum Linn (Trang et al., 2014), Polygala sabulosa, Cyathea phalerata (Brighente et al., 2008), as well as the stem bark from Dracontomelon dao(Blanco) Merr (Yamin et al., 2020).

Table II. The $\mathrm{IC}_{50}$ value of extract and fraction from $L$.

\begin{tabular}{lc}
\multicolumn{2}{c}{ domesticum seeds } \\
\hline \multicolumn{1}{c}{ Sample } & $\mathrm{IC}_{50}$ value $(\boldsymbol{\mu g} / \mathbf{m L})$ \\
\hline Methanol extract & $14.624 \pm 0.456$ \\
$n$-hexane fraction & $11.012 \pm 0.094$ \\
Ethyl acetat fraction & $8.938 \pm 0.031$ \\
Water fraction & $13.898 \pm 0.81$ \\
Vitamin C & $4.721 \pm 0.046$ \\
\hline
\end{tabular}

The DPPH is a free radical widely used to examine radical scavenging activity of plant extracts (Jamuna et al., 2012), pure compounds, food ingredients, and others (Koleva et al., 2002). Besides, this method is fast, reliable, reproducible, requires less energy, does not require sophisticated instruments, the reagents needed in this method are inexpensive (Jamuna et al., 2012, Koleva et al., 2002). An antioxidant compound's intrinsic ability to donate hydrogen atoms or electrons to homogeneously reactive radical compounds can be determined. This method is based on a decrease in the solubility of methanolic DPPH, which is caused by antioxidant 
compounds that donate their hydrogen (Rohman et al., 2010).

The antioxidant activity of extract and fractions is affected by the phenolic and flavonoid contents. This phenomenon is caused by the presence of a hydroxy group from those compounds. The strength of antioxidants by flavonoid compounds depends on the number of hydroxyl groups attached to ring B. The more hydroxyl groups are attached to ring $B$, the stronger the compound is in counteracting radicals. This is because the hydroxyl groups in ring B play a role in stabilizing the aryloxy radical (Cao et al., 1997). Besides, the existence of ortho-hydroxyl substitution in ring $\mathrm{B}$ or ring $\mathrm{A}$ is important in the inhibition of radicals, while substitution in other positions does not show a clear role in stabilizing radicals (Yokozawa et al., 1998). Table III showed the phenolic and flavonoid contents in the extract and fractions of $L$. domesticum seeds. The levels of phenolic and total flavonoid contents were ethyl acetate fraction > $n$-hexane $>$ water fraction $>$ crude extract, with the total phenolic contents of $58.25 \pm 0.501 ; 44.315 \pm 1.737 ; 39.454 \pm$ 0.446; and $31.028 \pm 0.605 \mathrm{mg}$ GAE/g dry samples, respectively. Meanwhile, the values of total flavonoids were $75.123 \pm 0.175 ; 59.626 \pm 0.268 ; 58.866 \pm 0.202$; and $56.175 \pm 0.175 \mathrm{mg} Q \mathrm{QE} / \mathrm{g}$ dry samples, respectively.

Table III. Total phenolic and flavonoid contents from $L$. domesticum seeds extract and fractions

\begin{tabular}{lcc}
\hline Sample & $\begin{array}{c}\text { Total phenolic } \\
\text { content (mg GAE/g } \\
\text { sample) }\end{array}$ & $\begin{array}{c}\text { Total flavonoid } \\
\text { content (mg QE/g } \\
\text { sample) }\end{array}$ \\
\hline $\begin{array}{l}\text { Methanol } \\
\text { extract }\end{array}$ & $31.028 \pm 0.605$ & $56.175 \pm 0.175$ \\
$\begin{array}{l}\text { Ethyl } \\
\text { acetate } \\
\text { fraction } \\
\begin{array}{l}n \text {-hexane } \\
\text { fraction }\end{array}\end{array}$ & $58.25 \pm 0.501$ & $75.123 \pm 0.175$ \\
$\begin{array}{l}\text { Water } \\
\text { fraction }\end{array}$ & $39.454 \pm 0.446$ & $59.626 \pm 0.268$ \\
\hline
\end{tabular}

Phenolic and flavonoid compounds are the most responsible for antioxidants activity. This is due to the hydroxy groups present in phenolic and flavonoid compounds in free radical scavenging (Saxena et al., 2012; Aryal et al., 2019). Based on the $\mathrm{IC}_{50}$ values in Table II, the total phenolic and flavonoid contents in the L. domesticum seeds are presented in Table III. It is known that the antioxidant activity of a material correlated with the phenolic and flavonoid contents in that material. The higher the total phenolic and flavonoid levels in the sample, the stronger the sample will be as an antioxidant. Correlation of total phenolic and flavonoid contents to radical activity ( $\mathrm{IC}_{50}$ values) in L. domesticum seeds is showed in Figure 2 and Figure 3, respectively. The relationship between radical activity $(y)$ with total phenol $(x)$ revealed a coefficient of determination $\left(\mathrm{R}^{2}\right)$ of 0.9182 , whereas total flavonoid content $(x)$ has an $\mathrm{R}^{2}$ of 0.7658 . The results suggested that phenolic compounds and flavonoids compounds contributed to $91.82 \%$ and $76.38 \%$ to free DPPH radical scavenging of extract and fraction of L. domesticum seeds. Also, it can be stated that the scavenging effect of extracts/fractions is not limited to phenolic and flavonoid compounds. The activity may also come from other antioxidant secondary metabolites in the extracts such as volatile oils, carotenoids, and vitamins (Javanmardi et al., 2003; Rohman et al., 2010; Mistriyani et al., 2018).

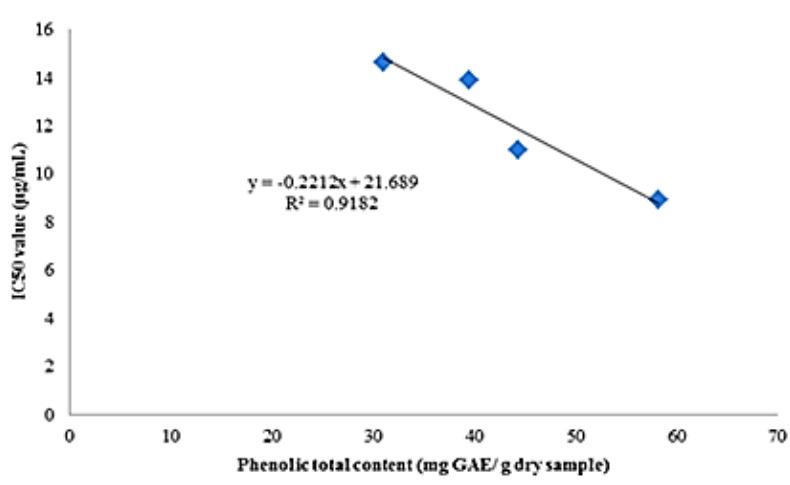

Figure 2. Correlation between of phenolic contents with the free DPPH radical activity $\left(\mathrm{IC}_{50}\right)$ value of extract and fractions of L. domesticum seeds 


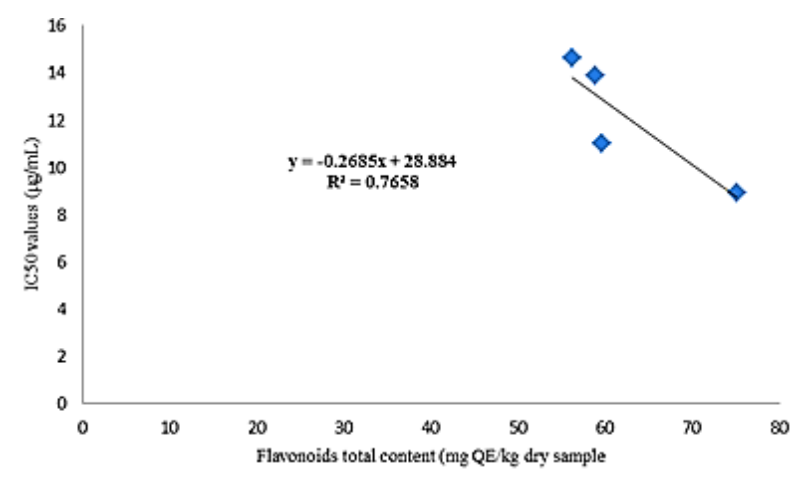

Figure 3. Correlation between of flavonoid contents with the free DPPH radical activity $\left(\mathrm{IC}_{50}\right)$ value of extract and fractions of L. domesticum seeds

\section{CONCLUSION}

The ethyl acetate fraction of L. domesticum seeds have a very strong activity as an antioxidant using the DPPH method, and the compounds most responsible as antioxidants are phenolic compounds and flavonoids. Ethyl acetate fraction can be further isolated to find out which compounds are most responsible as antioxidants.

\section{ACKNOWLEDGMENT}

We are grateful for the support of the Rector of Universitas Halu Oleo for providing generous support with the 2019 Basic Research Grant.

\section{REFERENCES}

Apridamayanti, P., Fajriaty, I., \& Hatita, E. (2018). Antioxidant activity and analgesic assessment of Lansium domesticum stem bark infusion. Nusantara Biosciences : Isea Journal of Biological Sciences, $\quad$ 10(2), 71-75. doi:10.13057/nusbiosci/n100201

Aryal, S., Baniya, M.K., Danekhu, K., Kunwar, K., Kunwar, P., Gurung, R., \& Koirala, N. (2019). Total Phenolic Content, Flavonoid Content and Antioxidant Potential of Wild Vegetables from Western Nepal. Plants, 8(4), 96. doi:10.3390/plants8040096

Brighente, I.M.C., Dias, M., Verdi, L.G., \& Pizzolatti, M.G. (2007). Antioxidant Activity and Total Phenolic Content of Some Brazilian Species.
Pharmaceutical Biology, 45(2), 156-161. doi:10.1080/13880200601113131

Cao, G., Sofic, E., \& Prior, R.L. (1997). Antioxidant and prooxidant behavior of flavonoids: structureactivity relationships. Free Radical Biology and Medicine, 22(5), 749-760. doi:10.1016/s08915849(96)00351-6

Fitriana, W.D., Ersam, T., Shimizu, K., \& Fatmawati, S. (2016). Antioxidant Activity of Moringa oleifera Extracts. Indonesian Journal of Chemistry, 16(3), 297-301. doi:10.22146/ijc.21145

Jamuna, Paulsamy, S.S., \& Karthika, K. (2012). Screening of in vitro antioxidant activity of methanolic leaf and root extracts of Hypochaeris radicata L. (Asteraceae). Journal of Applied Pharmaceutical Science, 2(7), 149-154. doi:10.7324/JAPS.2012.2722

Javanmardi, J., Stushnoff, C., Locke, E., \& Vivanco, J.M. (2003). Antioxidant activity and total phenolic content of Iranian Ocimum accessions. Food Chemistry, 83(4), 547-550. doi:10.1016/S03088146(03)00151-1

Khoo, H.E., Azlan, A., Kong, K.W., \& Ismail, A. (2016). Phytochemicals and Medicinal Properties of Indigenous Tropical Fruits with Potential for Commercial Development. Evidence-Based Complementary and Alternative Medicine, 2016, 7591951. doi:10.1155/2016/7591951

Klungsupya, P., Suthepakul, N., Muangman, T., RerkAm, U., \& Thongdon-A, J. (2015). Determination of Free Radical Scavenging, Antioxidative DNA Damage Activities and Phytochemical Components of Active Fractions from Lansium domesticum Corr. Fruit. Nutrients, 7(8), 6852-6873. doi:10.3390/nu7085312

Koleva, I.I., van Beek, T.A., Linssen, J.P.H., de Groot, A., \& Evstatieva, L.N. (2002). Screening of plant extracts for antioxidant activity: a comparative study on three testing methods. Phytochemical Analysis, 13(1), 8-17. doi:10.1002/pca.611

Maisuthisakul, P., Suttajit, M., \& Pongsawatmanit, R. (2007). Assessment of phenolic content and free radical-scavenging capacity of some Thai indigenous plants. Food Chemistry, 100(4), 14091418. doi:10.1016/j.foodchem.2005.11.032 
Manosroi, A., Chankhampan, C., Manosroi, W., \& Manosroi, J. (2013). Anti-proliferative and matrix metalloproteinase-2 inhibition of Longkong (Lansium domesticum) extracts on human mouth epidermal carcinoma. Pharmaceutical Biology, 51(10), 1311-1320. doi:10.3109/13880209.2013.790064

Manosroi, A., Jantrawut, P., Sainakham, M., Manosroi, W., \& Manosroi, J. (2012). Anticancer activities of the extract from Longkong (Lansium domesticum) young fruits. Pharmaceutical Biology, 50(11), 1397-1407. doi:10.3109/13880209.2012.682116

Mistriyani, Riyanto, S., \& Rohman, A. (2018). Antioxidant activities of Rambutan (Nephelium lappaceum L) peel in vitro. Food Research, 2(1), 119-123. doi:10.26656/fr.2017.2(1).150

Molyneux, P. (2004). The use of the stable free radical diphenylpicrylhydrazyl (DPPH) for estimating antioxidant activity. Songklanakarin Journal of Science and Technology, 26(2), 211-219.

Nur, S., Rumiyati, R., \& Lukitaningsih, E. (2017). Screening of Antioxidants, Anti-Aging and Tyrosinase Inhibitory Activities of Ethanolic and Ethyl Acetate Extracts of Fruit Flesh and Fruit Peel Langsat (Lansium domesticum Corr) In Vitro. Majalah Obat Tradisional, 22(1), 63-72. doi:10.22146/tradmedj.24342

de Oliveira, V.S., Ferreira, F.S., Cople, M.C.R., Labre, T.S., Augusta, I.M., Gamallo, O.D., \& Saldanha, T. (2018). Use of Natural Antioxidants in the Inhibition of Cholesterol Oxidation: A Review. Comprehensive Reviews in Food Science and Food Safety, 17(6), 1465-1483. doi:10.1111/15414337.12386

Olugbami, J.O., Gbadegesin, M.A., \& Odunola, O.A. (2014). In vitro evaluation of the antioxidant potential, phenolic and flavonoid contents of the stem bark ethanol extract of Anogeissus leiocarpus. African Journal of Medicine and Medical Sciences, 43(Suppl 1), 101-109.

Pandeya, A., Rayamajhi, S., Pokhrel, P., \& Giri, B. (2018). Evaluation of secondary metabolites, antioxidant activity, and color parameters of Nepali wines. Food Science and Nutrition, 6(8), 2252-2263. doi:10.1002/fsn3.794

Parthasarathi, S. \& Park, Y.K. (2015). Determination of total phenolics, flavonoid contents and antioxidant activity of different $\mathrm{mBHT}$ fractions: A polyherbal medicine. Pakistan Journal of Pharmaceutical Sciences, 28(6), 21612166.

Pham-Huy, L.A., He, H., \& Pham-Huy, C. (2008). Free Radicals, Antioxidants in Disease and Health. International Journal of Biomedical Science, 4(2), 89-96.

Piluzza, G. \& Bullitta, S. (2011). Correlations between phenolic content and antioxidant properties in twenty-four plant species of traditional ethnoveterinary use in the Mediterranean area. Pharmaceutical Biology, 49(3), 240-247. doi:10.3109/13880209.2010.501083

Rohman, A., Riyanto, S., Yuniarti, N., Saputra, W.R., Utami, R., \& Mulatsih, W. (2010). Antioxidant activity, total phenolic, and total flavonoid of extracts and fractions of red fruit (Pandanus conoideus Lam). International Food Research Journal, 17(1), 97-106.

Saeed, N., Khan, M.R., \& Shabbir, M. (2012). Antioxidant activity, total phenolic and total flavonoid contents of whole plant extracts Torilis leptophylla L. BMC Complementary and Alternative Medicine, 12, 221. doi:10.1186/14726882-12-221

Saewan, N., Sutherland, J.D., \& Chantrapromma, K. (2006). Antimalarial tetranortriterpenoids from the seeds of Lansium domesticum Corr. Phytochemistry, 67(20), 2288-2293. doi:10.1016/j.phytochem.2006.07.005

Sannigrahi, S., Mazuder, U.K., Pal, D.K., Parida, S., \& Jain, S. (2010). Antioxidant Potential of Crude Extract and Different Fractions of Enhydra fluctuans Lour. Iranian Journal of Pharmaceutical Research, 9(1), 75-82.

Saxena, M., Saxena, J., \& Pradhan, A. (2012). Flavonoids and Phenolic Acids as Antioxidants in Plants and Human Health. International Journal of Pharmaceutical Sciences Review and Research, 16(2), 130-134.

Sulastri, E., Zubair, M.S., Anas, N.I., Abidin, S., Hardani, R., Yulianti, R., \& Aliyah. (2018). Total Phenolic, Total Flavonoid, Quercetin Content and Antioxidant Activity of Standardized Extract of Moringa oleifera Leaf from Regions with Different Elevation. Pharmacognosy 
Journal, 10(6s), s104-s108. doi:10.5530/pj.2018.6s.20

Tilaar, K., Junardy, F.D., \& Subroto, E. (2018). Safety and Efficacy Evaluation on Combination of Lansium domesticum Fruit Extract and Hibiscus rosa-sinensis Flower Extract as Lightening Agent for Cosmetic. International Journal of Pharma Medicine and Biological Sciences, $\quad 7(3), \quad 67-70$. doi:10.18178/ijpmbs.7.3.67-70

Tilaar, M., Wih, W.L., Ranti, A.S., Wasitaatmadja, S.M., Suryaningsih, Junardy, F.D., \& Maily. (2008). Review of Lansium domesticum Corrêa and its use in cosmetics. Boletin Latinoamericano y del Caribe de Plantas Medicinales y Aromaticas, 7(4), 183-189.

Trang, D.H.T., Son, H.L., \& Trung, P.V. (2018). Investigation on the in vitro antioxidant capacity of methanol extract, fractions and flavones from Oroxylum indicum Linn bark. Brazilian Journal of Pharmaceutical Sciences, 54(1), 1-7. doi:10.1590/s2175-97902018000117178

Yamin, Ruslin, Sartinah, A., Ihsan, S., Kasmawati, H., Suryani, Andriyani, R., Asma, Adjeng, A.N.T., \& Arba, M. (2020). Radical scavenging assay and determination Flavonoid and Phenolic total of extract and Fractions of Raghu bark (Dracontomelon dao (Blanco) Merr). Research Journal of Pharmacy and Technology, 13(5), 23352339. doi:10.5958/0974-360X.2020.00420.5

Yapp, D.T.T. \& Yap, S.Y. (2003). Lansium domesticum: skin and leaf extracts of this fruit tree interrupt the lifecycle of Plasmodium falciparum, and are active towards a chloroquine-resistant strain of the parasite (T9) in vitro. Journal of Ethnopharmacology, 85(1), 145-150. doi:10.1016/s0378-8741(02)00375-6

Yokozawa, T., Chen, C.P., Dong, E., Tanaka, T., Nonaka, G.I., \& Nishioka, I. (1998). Study on the inhibitory effect of tannins and flavonoids against the 1,1-diphenyl-2 picrylhydrazyl radical. Biochemical Pharmacology, 56(2), 213222. doi:10.1016/s0006-2952(98)00128-2

Widodo, H., Sismindari, Asmara, W., \& Rohman, A. (2020). Antioxidant activities of methanolic extract and its fractions of Baccaurea racemosa and Macaranga subpeltata leaves. Food Research, 4(1), 127-134. doi:10.26656/fr.2017.4(1).144 